\title{
Regulatory T Cells in GVHD Therapy
}

\author{
Wen-wen Guo ${ }^{1 \dagger}$, Xiu-hua Su ${ }^{2 \dagger}$, Ming-yang Wang ${ }^{1}$, Ming-zhe Han ${ }^{1}$, Xiao-ming Feng ${ }^{1 *}$ \\ and Er-lie Jiang ${ }^{1 *}$ \\ 1 State Key Laboratory of Experimental Hematology, Institute of Hematology and Hospital of Blood Disease, Chinese \\ Academy of Medical Sciences and Peking Union Medical College, Tianjin, China, ${ }^{2}$ School of Medicine, Cheeloo College of \\ Medicine, Shandong University, Jinan, China
}

\section{OPEN ACCESS}

Edited by:

Ping Zhang,

Fred Hutchinson Cancer Research

Center, United States

Reviewed by:

LiXuan,

Southern Medical University, China

Paul G. Schlegel,

University Children's Hospital

Würzburg, Germany

Mauro Di lanni,

University of Studies G. d'Annunzio

Chieti and Pescara, Italy

*Correspondence:

Xiao-ming Feng

fengxiaoming@ihcams.ac.cn

Er-lie Jiang

jiangerlie@163.com

${ }^{\dagger}$ These authors have contributed equally to this work

Specialty section:

This article was submitted to Alloimmunity and Transplantation,

a section of the journal

Frontiers in Immunology

Received: 20 April 2021 Accepted: 02 June 2021

Published: 18 June 2021

Citation:

Guo $W-w$, Su X-h,

Wang $M-y$, Han $M-z$,

Feng $X-m$ and Jiang E-I (2021) Regulatory T Cells in GVHD Therapy.

Front. Immunol. 12:697854. doi: 10.3389/fimmu.2021.697854
Graft versus host disease (GVHD) is a common complication and the leading cause of morbidity and mortality after allogeneic hematopoietic stem cell transplantation (alloHSCT). Pharmacological immunosuppression used in GVHD prophylaxis and treatment lacks specificity and can increase the likelihood of infection and relapse. Regulatory $T$ lymphocytes (Tregs) play a vital role in restraining excessive immune responses and inducing peripheral immune tolerance. In particular, clinical trials have demonstrated that Tregs can prevent and treat GVHD, without increasing the risk of relapse and infection. Hence, adoptive transfer of Tregs to control GVHD using their immunosuppressive properties represents a promising therapeutic approach. To optimally apply Tregs for control of GVHD, a thorough understanding of their biology is necessary. In this review, we describe the biological characteristics of Tregs, including how the stability of FOXP3 expression can be maintained. We will also discuss the mechanisms underlying Tregsmediated modulation of GVHD and approaches to effectively increase Tregs' numbers. Finally, we will examine the developing trends in the use of Tregs for clinical therapy.

Keywords: regulatory $\mathrm{T}$ cells, acute graft versus host disease, chronic graft versus host disease, hematopoietic stem cell transplantation, adoptive cellular therapy

\section{INTRODUCTION}

Allogeneic hematopoietic stem-cell transplantation (allo-HSCT) is a curative therapy for patients with many hematological malignancies; however, graft versus host disease (GVHD) is a major obstacle to the utility of allo-HSCT as it contributes to subsequent mortality and morbidity. GVHD can be classified into acute (aGVHD) and chronic (cGVHD) forms and is characterized by attack of host tissues by donor lymphocytes, owing to disparities in major histocompatibility complex (MHC) molecules or minor histocompatibility antigens (mHAs), which elicit an immune response. Although the immunosuppressive agents, cyclosporine and methotrexate, are administered after allo-HSCT as prophylaxis, aGVHD incidence rates range from 20 to $80 \%$ (1), while 6 to $80 \%$ of patients develop cGVHD. Glucocorticoids are the first-line treatment for GVHD (1-3); however, only $50-80 \%$ and $40-50 \%$ of patients with aGVHD and cGVHD, respectively, respond to steroid therapy $(1,2)$. If patients are resistant to glucocorticoids, overall survival rates are dismal at only 5 to $30 \%$ (4). At present, there is no consensus on standard second-line treatment. This situation emphasizes the need for development of innovative therapeutic strategies to control pathological immune responses following allo-HSCT.

In recent years, with increased understanding of regulatory cell populations, cellular therapy, particularly adoptive transfer of $\mathrm{CD} 4^{+} \mathrm{CD} 25^{+}$regulatory $\mathrm{T}$ cells (Tregs), has attracted more attention (5). 
In 1995, Sakaguchi (6) first identified a population of $\mathrm{CD}^{+}$cells expressing high levels of IL-2 $\alpha$-chain receptor (CD25) in lymph nodes and spleens of BALB/c nu/+ mice, which could protect thymectomized mice from autoimmune disease and contribute to maintaining peripheral immune tolerance by suppressing immune responses against self- or non-self-antigens. Later, transcription factor forkhead box P3 (FOXP3) was identified as specifically expressed in Tregs and as making an indispensable contribution to controlling Treg development and suppressive function (7), deepening the understanding of this cell subset. The IL-7 receptor, CD127, is a biomarker inversely correlated with FOXP3 expression and Tregs' inhibitory activity (8). Since FOXP3 is expressed intracellularly, the combination of CD4, CD25, and CD127 has been widely used to isolate Tregs and $\mathrm{CD} 4^{+} \mathrm{CD} 25^{+} \mathrm{CD} 127^{-} \mathrm{T}$ cells are now referred to as Tregs. In addition to self-tolerance, Tregs also have a vital role in inducing tolerance of alloantigens (9-11). at url breaking operator Taylor et al. (9) found that CD25-depleted $\mathrm{CD} 4^{+}$cells showed increased responsiveness to allogeneic antigens and that addition of $\mathrm{CD} 4^{+} \mathrm{CD} 25^{+}$cells had a potent capacity to regulate $\mathrm{CD}^{+} \mathrm{T}$ cell alloresponses. Meanwhile, $\mathrm{CD} 4^{+} \mathrm{CD} 25^{+}$cells were found to induce transplantation tolerance in experiments involving transfer of $\mathrm{CD} 4{ }^{+} \mathrm{CD} 25^{+}$Tregs from primarily tolerant mice to syngeneic recipients, which protected recipients from graft at url breaking operator rejection $(10,11)$. Based on the suppressive capacity of $\mathrm{CD} 4^{+} \mathrm{CD} 25^{+}$Tregs toward alloreactive T cells, Cohen et al. (12) demonstrated that removal of $\mathrm{CD} 4^{+} \mathrm{CD} 25^{+}$Tregs from the graft during transplantation accelerated the occurrence of GVHD, while addition of freshly isolated or ex vivo-expanded $\mathrm{CD} 4{ }^{+} \mathrm{CD} 25^{+}$Tregs could delay or even prevent GVHD after allo-HSCT. Tregs were found to prevent GVHD for a long time due to their survival and expansion in vivo after transplantation in bone marrow transplantation models (13). Besides, adoptive transfer of Tregs could accelerate the immune reconstitution after transplantation, owing to the prevention of damage of the thymic and secondary lymphoid microenvironment caused by GVHD, which was important for $\mathrm{T}$ cell immunity (14). Given these properties of suppressing excessive allogeneic responses, cellular therapy, based on adoptive transfer of Tregs to control GVHD has been the focus of study $(12,15-18)$.

$\mathrm{T}$ cells with immunosuppressive function are a diverse group of cells. Except for $\mathrm{CD}^{+}$Tregs, it has been confirmed that $\mathrm{CD}^{+}$Tregs can regulate excessive immune responses to control GVHD in animal models as well (19). Being different from CD4 ${ }^{+}$Tregs, the characteristics of $\mathrm{CD}^{+}$Tregs are controversial, and specific surface markers to isolate them have not reached agreement (20). In addition to $\alpha \beta \mathrm{T}$ cells, $\gamma \delta \mathrm{T}$ cells are also capable of immunoregulation (21). Regulatory $\gamma \delta \mathrm{T}$ cells ( $\gamma \delta$ Tregs) function to regulate GVHD, which can be induced by granulocyte colonystimulating factor (G-CSF) (22). In this review, we will focus on $\mathrm{CD}^{+} \mathrm{CD} 25^{+} \mathrm{FOXP}^{+}$Tregs.

Tregs have the potential to attenuate GVHD without impairing the graft versus leukemia (GVL) effect significantly, making the adoptive transfer of Tregs a promising strategy for treatment of GVHD $(23,24)$; however, translation of this phenomenon into clinical application continues to face numerous challenges, particularly the instability of Tregs and the difficulties in obtaining sufficient quantities of cells to transfer. In this review, we discuss the biological characteristics of Tregs administered in the context of GVHD. Furthermore, we focus on how to solve the problem of insufficient Treg numbers for adoptive transfer and discuss the clinical prospects for application of Tregs.

\section{THE THEORETICAL BASIS OF TREGS' ADMINISTRATION TO TREAT GVHD}

\section{Tregs' Definition and Function}

Tregs account for only $5-10 \%$ of $\mathrm{CD}^{+} \mathrm{T}$ cells in peripheral blood, but they are essential for maintenance of immunological tolerance $(6,9-12)$. FOXP3 is specifically expressed in Tregs and acts as a major regulator that controls their development and stability $(7,25)$. Inactivating mutations or specific deletion of FOXP3 causes a lethal autoimmune syndrome due to a deficiency of Tregs (7). Tregs can be roughly divided into two groups according to their developmental origin. First, thymic Tregs (tTregs), also known as nTregs, are generated when $\mathrm{CD} 4^{+}$ single-positive thymocytes encounter self-antigen stimuli in the thymus during development; T cell receptors (TCRs) expressed on tTregs mainly recognize self-antigens, which means tTregs have advantages in preventing autoimmune disease $(26,27)$. The other type of Tregs develops from naïve $\mathrm{CD} 4^{+} \mathrm{T}$ cells in the periphery following antigen encounter, through exposure to appropriate cytokines, such as transforming growth factor- $\beta$ (TGF- $\beta$ ) and IL-2 (28-31). When this pathway occurs in vivo, the resulting $\mathrm{FOXP}^{+}$Treg cells are referred to as peripherally induced Tregs (pTregs), whereas, when it takes place in vitro, they are termed induced Tregs (iTregs) (28-31). Relative to tTregs, pTregs are considered to play an important role in maintaining mucosal tolerance, as the TCRs expressed on pTregs can also be specific for foreign antigens from commensal bacteria (32). In mice, neuropilin-1 (NRP1) is selectively expressed on nTregs rather than pTregs, whether they are generated in vivo or in vitro, and can be used to distinguish nTregs from pTregs (33). Based on analysis of NRP1, Yadav et al. (33) found that NRP-1 $1^{\text {lo }}$ Tregs have similar ability to suppress autoimmune responses as NRP- $1^{\text {hi }}$ Tregs, but that the function of NRP- $1^{\text {lo }}$ Tregs was compromised in inflammatory and lymphopenic environments, relative to that of NRP- ${ }^{\text {hi }}$ Tregs. Unfortunately, no cellular markers have been found to distinguish nTregs and pTregs in humans. Currently, the evaluation of Treg-specific demethylated region (TSDR), a conserved CpG-rich region within the FOXP3 locus, is the only way to distinguish nTregs, and the stability of FOXP3 expression is positively correlated with DNA demethylation at the TSDR (34). The TSDR is completely demethylated in nTregs, but iTregs exhibit incomplete demethylation of TSDR and are prone to losing FOXP3 expression and suppression ability (34), which may explain their instability in inflammatory environments.

\section{FOXP3 Stability in Tregs}

FOXP3, which is regarded as a Treg lineage-specific factor, acts as a master regulator of gene expression in Tregs and exerts 
regulatory functions at the transcriptional, epigenetic, and posttranscriptional levels (35). Continuous FOXP3 expression is indispensable for maintenance of the Tregs' immunosuppressive phenotype; however, under certain proinflammatory conditions, Tregs are prone to losing FOXP3 expression and transdifferentiating into pathogenic $\mathrm{T}$ cells, also referred to as exTregs (36). Therefore, it is particularly important to enhance FOXP3 expression in Tregs to ensure that they continue to exert immunosuppressive activity under post-transplantation conditions. Our laboratory and others found that liver kinase b1 (LKB1) is essential for maintaining the stability of FOXP3 expression and the suppression capacity of Tregs in murine models by deletion of the gene encoding LKB1 specifically in Tregs (37-40). We also found that LKB1 may prevent STAT4mediated methylation of the TSDR, ensuring stable FOXP3 expression (37). Furthermore, we observed dramatically decreased expression of FOXP3 in human Tregs owing to knockdown of the LKB1 gene (40). MicroRNAs (miRNAs) can govern the expression of protein-coding genes at the posttranscriptional level (41). Cobb et al. found that miRNA profiles expressed in Tregs were distinct from those in conventional $\mathrm{CD}^{+} \mathrm{T}$ cells and confirmed that eliminating miRNAs by conditional deletion of Dicer (an RNAse III enzyme needed to generate functional miRNA) could influence the development of Tregs in the thymus, reduce the number of Tregs in the periphery, and down-regulate FOXP3 expression (42). Moreover, mice lacking Dicer were prone to developing immune pathology (42). Nevertheless, the detailed mechanisms underlying interactions between miRNAs and FOXP3 are not fully understood. MiR$146 \mathrm{~b}$ can restrain FOXP3 protein levels by targeting TNF receptor-associated factor 6 (TRAF6) and suppressing the NF- $\kappa$ B pathway (43). Conversely, MiR-146b antagomirs function to promote the proliferation and suppressive ability of Tregs (43). Further, miR-4281 interacts directly with the TATA-box motif in the FOXP3 promoter, thereby strongly increasing FOXP3 expression (44). Similarly, miR-142-3p knockdown upregulates FOXP3 expression and enhances the anti-apoptotic and suppressive function of Tregs (45). Ectopic expression of FOXP3 can confer partial Tregs miRNA profiles, demonstrating that FOXP3 may control Treg-specific miRNA expression (42). Hence, miRNAs may have important roles in regulating Tregs' biology and potentially represent strong targets for intervention against GVHD.

\section{Characteristics of GVHD}

The clinical manifestations of aGVHD include an exaggerated inflammatory response, usually involving the skin, intestine, and liver, which occurs within the first 100 days after allo-HSCT (46). Ferrara categorized the occurrence of aGVHD into three continuous phases (47): First, the activation of antigen presenting cells (APCs) by proinflammatory cytokines and danger-associated molecular pattern molecules (DAMPs), which originate from damaged host tissues in response to primary disease and conditioning regimens (47, 48); Second, after encountering activated APCs, donor $\mathrm{T}$ cells are rapidly expanded and differentiated into effector T cells (Teffs); Finally, Teffs migrate to target organs with the help of chemokines, causing further damage to host tissues $(47,48)$. Compared with aGVHD, the mechanisms underlying cGVHD are not clearly understood. The manifestations of cGVHD are similar to those of autoimmune diseases, involve more organs than aGVHD, and usually develop more than 100 days after allo-HSCT (47). Overall, GVHD can be considered as an imbalance between the effector and regulatory arms of the immune system and is characterized by an overproduction of inflammatory cytokines $(49,50)$.

Numbers of Tregs in the peripheral blood and target organs decline in the inflammatory environment of GVHD, which, in turn, increases GVHD severity $(51,52)$. Conversely, when Tregs are co-transferred in equal numbers with $\mathrm{CD} 4^{+} \mathrm{T}$ cells, GVHD can be modestly inhibited in animal models (53). Furthermore, improving early reconstitution of Tregs can prevent GVHD by inhibiting the rapid oligoclonal proliferation of pathogenic $\mathrm{CD} 4^{+}$ Teffs (54). Understanding the mechanisms underlying immune tolerance induction by Tregs can provide information about potential therapeutic targets of GVHD.

\section{Role of Tregs in GVHD}

In general, Tregs can regulate and suppress excessive responses to alleviate GVHD using both contact and non-contactdependent mechanisms, which can be classified into four categories: cytolysis, secretion of inhibitory cytokines, metabolic disruption, and targeting of dendritic cells (DCs) (55) (Figure 1). Perforin and granzyme B secreted by Tregs can kill Teffs directly (55). Furthermore, inhibitory cytokines, such as interleukin-10 (IL-10), IL-35, and TGF- $\beta$, which are expressed by Tregs, are required for Tregs' function (48, 55-57). IL-2 is indispensable for the homeostasis of both Tregs and Teffs. Tregs consume high amounts of IL-2 in local sites, since CD25 (the IL-2 receptor alpha chain) is highly expressed by Tregs, and this may lead to IL-2 starvation of Teffs $(48,55)$. The reciprocal relationship between Tregs and DCs performs a vital and complex function in controlling GVHD. In addition to killing reactive $\mathrm{T}$ cells via cell-cell contact, Tregs can act on multiple target cells, particularly DCs. Moreover, Tregs appear to have a more stable association with DCs than that with $\mathrm{CD} 4^{+} \mathrm{T}$ helper $\left(\mathrm{T}_{\mathrm{H}}\right)$ cells in NOD mouse models, which prevents subsequent interaction between DCs and $\mathrm{T}_{\mathrm{H}}$ cells (58). Thus, the interaction between Tregs and DCs may have a core role in the mechanisms underlying Tregs-mediated immune suppression $(58,59)$. DCs are considered the most powerful APCs and have a dual role in GVHD development (60-65); host DCs or de novo generated donor DCs both contribute to T-cell priming by presenting alloantigens in the context of HLA molecules, as well as providing secondary signals to promote full $\mathrm{T}$ cell activation (60-63). Tregs constitutively express cytotoxic T-lymphocyte antigen 4 (CTLA-4), the affinity of which for CD80/86 expressed on DCs is superior to that for CD28, hindering complete T-cell activation via blocking the binding of CD28 and CD80/86 (66). Further, Tregs can facilitate the removal and degradation of CD80/86 from DCs via CTLA-4 through the process of trans-endocytosis (67). In addition, immunosuppressive cytokines, such as IL-10, released by Tregs can interfere with DC activation and antigen presentation (68). Tregs can hamper DC 


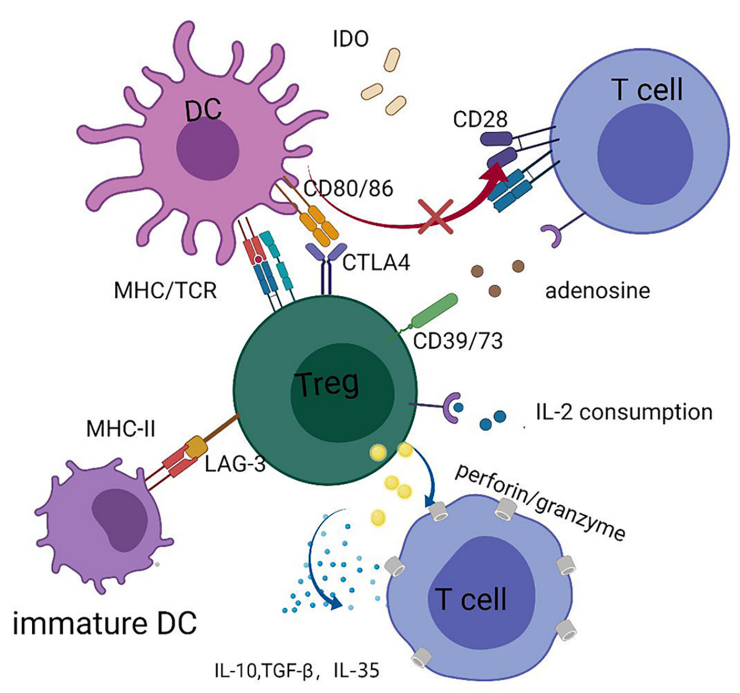

FIGURE 1 | Tregs can secrete perforin and granzyme B to kill Teffs directly and secret IL-10, IL-35, and TGF- $\beta$, inhibitory cytokines to suppress functions of Teffs; Tregs can cause IL-2 starvation of Teffs via highly expressing CD25. Tregs exert the function of suppression by interaction with DCs, such as downregulating the expression of CD80/CD86 in DCs and interfering with the maturation of DCs. Tryptophan is vital for the survival of Teffs and Tregs can enhance the expression of indoleamine 2, 3dioxygenase (IDO) in DCs, which accelerates the decomposition of tryptophan. Adenosine triphosphate (ATP) is a pro-inflammatory factor, and CD39/73 expressed on Tregs can transform ATP to adenosine, an antiinflammatory factor.

maturation, rendering them deficient in priming $\mathrm{T}$ cell activation, and lymphocyte activation gene 3 (LAG-3), expressed by Tregs, may play a dominant role in the process of DC maturation (69-72). Recently, Mavin et al. (70) discovered that human Tregs can modulate DC function through disturbing their reprogramming during maturation, which may involve the NF- $\kappa \mathrm{B}$ signaling pathway and WNT5A expression. In addition to influencing the activity of DCs themselves, Tregs may alter DC function; for example, Treg-treated DCs tend to skew $\mathrm{CD}^{+}$naïve $\mathrm{T}$ cell polarization and impair $\mathrm{CD}^{+}$Teffs function in inducing GVHD (70). In contrast, DCs can induce donor $\mathrm{T}$ cell tolerance by promoting the expansion and function of Tregs, thus protecting them from GVHD $(60,73)$. Our laboratory found that LKB1 has an important role in DCs to increase the number of Tregs, which has also been confirmed in other studies (74-76). Granulocytemacrophage colony-stimulating factor (GM-CSF) functions to increase $\mathrm{CD}^{+} \mathrm{CD}^{-}$DC numbers, thus preferentially inducing Tregs expansion, and alleviating tissue damage in a cGVHD mouse model (77). The relationship between DCs and Tregs intricately controls GVHD, and further research is warranted to inform the development of new strategies to prevent GVHD.

\section{Tregs in GVL}

$\mathrm{T}$ cells originating from donors can eliminate remaining tumor cells, hence allo-HSCT is considered the only curative therapy for numerous malignant hematological diseases. This also means that immunosuppressive Tregs controlling GVHD by inhibiting the initial activation of alloreactive $T$ cells may compromise the GVL effect, thereby increasing the risk of relapse and infection. Experiments in several animal models have revealed that Treg therapy can suppress GVHD while maintaining GVL, thus separating GVHD from GVL $(78,79)$. This may involve Tregmediated inhibition of excessive donor $\mathrm{T}$ cell proliferation and downregulation of serum proinflammatory cytokine levels, while not interfering with the activation of conventional $\mathrm{T}$ cells (Tcons), particularly the ability of $\mathrm{CD}^{+} \mathrm{T}$ cells to kill tumors (78); however, some preclinical experiments have also demonstrated that $\mathrm{CD}^{+}{ }^{+}$iTregs can partially impair GVL in a mouse model, with animals suffering short-term leukemia relapse $(80,81)$. The combination therapy of $\mathrm{CD}^{+}$iTregs and $\mathrm{CD}^{+}$iTregs may provide a new way to solve the problem because the GVL effect can be preserved by $\mathrm{CD}^{+}$iTregs, and $\mathrm{CD}^{+}$iTregs function to attenuate GVHD in the meanwhile, which achieves the effect of one plus one being greater than two (81). Excitingly, Treg-based therapy has seldom been found to have a detrimental influence on the risk of relapse and infection in clinical trials $(18,82-84)$.

\section{TREGS' EXPANSION FOR GVHD THERAPY}

\section{Expansion Ex Vivo}

As mentioned above, Tregs account for a small proportion of $\mathrm{CD}^{+} \mathrm{T}$ cells in the peripheral blood. Therefore, the numbers of Tregs freshly isolated from donors are far from sufficient to cater for clinical infusion requirements. Furthermore, the purity of Tregs isolated from donors is sub-optimal, as there is a lack of specific markers to distinguish Tregs from Tcons. Currently, Tregs isolated by leukapheresis from healthy donors and expanded by exposure to $\alpha \mathrm{CD} 3 / \alpha \mathrm{CD} 28$ beads and IL- 2 stimulation are a common source for cellular therapy in the clinic (85) (Figure 2). Tregs expanded by using good manufacturing practices-compatible protocol were confirmed to prevent GVHD and retain GVL effectively in animal models (86). The approach of automated clinical-grade expansion of Tregs ex vivo has been developed to improve the purity and quantity of the infused Tregs $(85,87)$. Nevertheless, the technology to isolate and expand Tregs is complex and costly; hence, new strategies to produce sufficient functional Tregs are required.

Although iTregs are intrinsically unstable, adoptive transfer of iTregs may also function to control GVHD $(53,88,89)$. Notably, iTregs can overcome the problem of lack of sufficient cell quantity, as they can be manufactured abundantly ex vivo. Further, alloantigen-specific iTregs are considered more effective than polyclonal Tregs as they directly target specific antigens (29, 88). Nevertheless, iTregs are prone to lose FOXP3 expression, particularly under inflammatory conditions, which limits their therapeutic activity in GVHD $(29,90)$. There have been attempts to optimize iTregs' stability (Figure 2). Kasahara et al. (88) found 

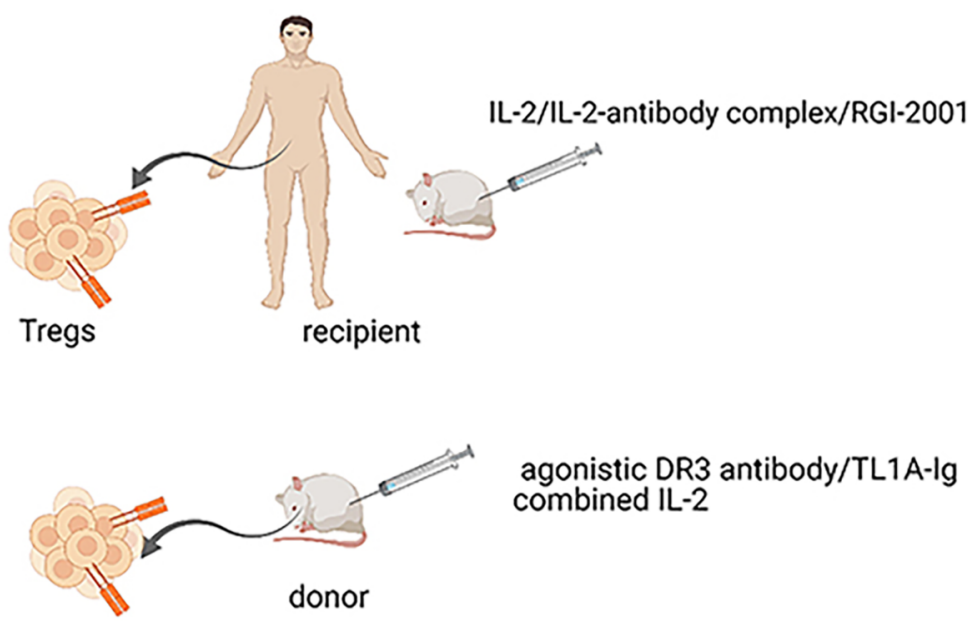

(A)

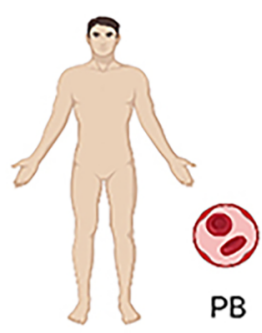

healthy donor

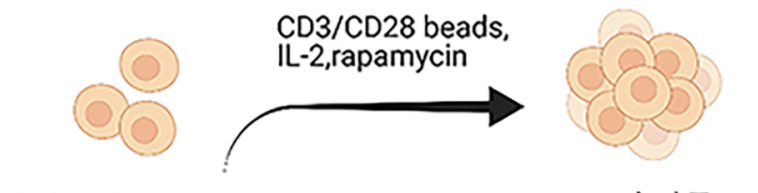

isolated Tregs

expanded Tregs

$\diamond$

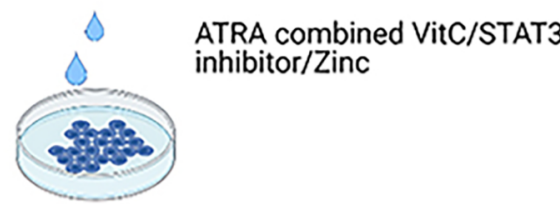

induced Tregs

FIGURE 2 | Treg expansion. (A) Expansion of Tregs in recipients and donors. Administration of low-dose IL-2 can expand Tregs of hosts preferentially in vivo since a high-affinity IL-2 receptor is expressed highly on Tregs. Considering IL-2 can also enhance the activation of Teffs, antibody-IL-2 complex is created, which can electively expand Tregs in vivo due to altering the structure of IL-2. Besides, RGI-2001 also has the function to accelerate the expansion of Tregs in vivo. The effectiveness of these cells has been tested in human and animal models. Reagents to expand Tregs of donors have been administrated in animal models, such as agonistic antibody against $\alpha \mathrm{DR} 3$ and TL1A-Ig combined with IL-2. (B) Expansion of Tregs isolated from donors in vitro and methods to improve iTregs' stability. Tregs isolated from healthy donors and expanded in vitro are the most common source at the expense of complex technologies and costly prices. Because of the unstable properties of iTregs, methods have been tried to improve its stability, such as the combination of all-trans retinoic acid and vitamin C, administration of STAT3 inhibitor, and the supplementation of Zinc.

that stable iTregs could be generated using a combination of alltrans retinoic acid and vitamin C. Vitamin C-treated iTregs significantly alleviated GVHD symptoms in murine models compared with untreated iTregs. Further, iTregs treated with STAT3 inhibitor exhibited dramatically enhanced suppression ability and achieved stability via high levels of FOXP3 demethylation (91). Furthermore, STAT3 phosphorylationinhibited iTregs have potent function in preventing xenogeneic GVHD by reducing excess immune responses caused by alloreactive $\mathrm{T}$ cells (92). Zinc supplementation may also increase iTreg numbers while maintaining their stability by prolonging FOXP3 expression (93). Enhancing iTregs' stability will solve the problem of insufficient Treg quantity for the requirements of clinical application.

\section{Expansion In Vivo}

Fujioka et al. (94) found that a low ratio of Tregs to $\mathrm{CD} 4^{+} \mathrm{T}$ cells in the early stage after allo-HSCT can predict impending 
aGVHD. Our laboratory results also suggest that Tregs from patients with aGVHD become defective in terms of their stability, survival, and suppressive function (40). Expansion of Tregs in recipients after allo-HSCT may be a promising strategy to alleviate GVHD (Figure 2). It is established that IL-2 is vital for the development, proliferation, and activity of Tregs (95), which can react to low concentrations of IL-2 by expressing high levels of a high-affinity IL-2 receptor (CD25). Administration of low-dose IL-2 in cGVHD patients was associated with preferential expansion of Tregs in vivo and attenuated the symptoms in certain patients $(96,97)$. Notably, IL-2 can also target many other cells, including promoting conventional $\mathrm{T}$ cell activation, and the appropriate effective dose for controlling GVHD is difficult to manage (95). Trotta et al. (98) generated a human antibody against IL-2 and combination with the antibody altered IL-2 conformation. The antibody-IL-2 complex could considerably and selectively expand Tregs in vivo and was effective in protecting mice from GVHD. Recently, Hirai et al. (99) innovatively engineered an orthogonal IL-2/IL-2 receptor (IL-2R) pair. The results demonstrated that transduced Tregs with orthogonal IL-2R were selectively expanded by orthogonal IL-2 stimulation without increasing other $\mathrm{T}$ cell subsets in murine models. Besides, this method did not reduce the function of Tregs and improved graft tolerance. Infusion of RGI-2001, a liposomal formulation carrying $\alpha$-galactosylceramide dramatically improved the survival of mice with aGVHD by enhancing the expansion of alloantigen specific $\mathrm{CD} 4{ }^{+} \mathrm{CD} 25^{+}$Tregs in vivo; notably, administration of RGI-2001 did not abrogate GVL (100). Further, a clinical trial of RGI-2001 showed that the incidence of severe GVHD was lower in responders than in non-responders (101).

In addition to expanding Tregs in hosts, methods to increase the number of donor Tregs for transfer in vivo have been attempted (Figure 2). An agonistic antibody against death receptor $3(\alpha \mathrm{DR} 3)$ has been found to enhance $\mathrm{CD} 4^{+} \mathrm{FOXP} 3^{+}$ Treg proliferation in vivo when administered to the donor, thus increasing the percentage of Tregs in the graft (102-104). Further, $\alpha \mathrm{DR} 3$-treated Tregs demonstrated potent proliferation and suppression abilities when transferred to host mice. The severity of GVHD in recipient mice receiving grafts from $\alpha \mathrm{DR} 3-$ treated donors was significantly less than that in isotype-treated donors (102-104). Similarly, TL1A-Ig (a soluble fusion protein from the natural ligand of tumor necrosis factor superfamily receptor 25 (TNFRSF25)) combined with IL-2 led to marked Treg expansion in donors via respective targeting of TNFRSF25 and CD25 in vivo. Adoptive transfer of Tregs from donors treated with TL1A-Ig/IL-2 effectively protected recipients from GVHD $(16,17)$. Furthermore, preclinical trial data suggest that GVHD after allo-HSCT can be controlled in patients with low numbers of Tregs stimulated by TL1A-Ig combined with IL-2, as this method of amplification can enhance Tregs' suppressive activity (16). Reagents found to increase Tregs' numbers and promote their inhibitory function in the donor may be used to develop new strategies for expanding Tregs ex vivo in the future.

\section{NEW SOURCES OF TREGS FOR GVHD}

\section{Third-Party Tregs}

In animal models and clinical trials, donors have been the most common source of Tregs used to modulate GVHD. As $\mathrm{CD} 4{ }^{+} \mathrm{CD} 25^{+} \mathrm{FOXP}^{+}$Tregs are scarce in the peripheral blood and HLA-matched donors are not always available, the efficacy and safety of Tregs from other sources have been evaluated for use in GVHD control (105). Tregs derived from a third-party [umbilical cord blood (UCB)] could confer protection from GVHD in a xenogeneic GVHD mouse models (106). Mice prophylactically injected with UCB-derived Tregs achieved better GVHD scores and overall survival rates than those receiving peripheral blood mononuclear cells (PBMCs) only (106). Another study found that Tregs derived from thirdparty mice could inhibit GVHD development compared with those originating from donors or hosts. Although the optimal therapeutic effect was observed in mice treated with donor Tregs, third-party Tregs could still be considered as a promising alternative source (105). Large numbers of Tregs can be isolated from pediatric thymuses, which are generally removed during cardiac surgery (107). Expanded thymic Tregs manifest stable FOXP3 expression and even maintain inhibitory ability under inflammation conditions. Furthermore, thymic Tregs more effectively protected mice from GVHD than Tregs derived from peripheral blood in xenogeneic GVHD mouse models. Therefore, pediatric thymuses may become an alternative source of functional Tregs (107).

\section{CAR Tregs}

Compared with polyclonal Tregs, alloantigen-specific Tregs, particularly those with chimeric antigen receptors (CARs), have the advantage of being able to achieve specific immunosuppression using fewer cells (108). CAR technology confers Tregs with superior ability to identify whole proteins expressed in cells, dispensing with HLA molecule restriction. MacDonald et al. (108) created alloantigen-specific Tregs using a CAR targeting HLA-A2, which is commonly mismatched in transplantation, and the A2-CAR Tregs maintained phenotypic stability and suppressive function. Surprisingly, the A2-CAR Tregs prominently delayed GVHD development and improved mouse survival compared with polyclonal Tregs in xenogeneic GVHD models. Further, owing to their larger numbers in circulation and considerable proliferation rates, $\mathrm{CD} 4^{+} \mathrm{T}$ cells can be transduced to express both A2-CAR and FOXP3 (109). These genetically modified $\mathrm{CD} 4^{+} \mathrm{T}$ cells (A2-CAR/FOXP3 $\mathrm{CD} 4^{+}$ Tregs) obtained a stable inhibitory phenotype and could suppress inflammation responses. Further, A2-CAR/FOXP3 $\mathrm{CD}^{+}$Tregs could significantly alleviate inflammatory pathology in a GVHD mouse model (109).

Third-party and engineered Tregs raise the prospect of universal Tregs, which could be provided as off-the-shelf products for use in patients (110). Universal donor Tregs can be manufactured to reduce immunogenicity by knocking out classical HLA molecules and knocking in non-canonical HLA molecules, such as HLA-E or HLA-G, thus escaping host 
immune system recognition (110). With advances in genome editing technology, induced pluripotent stem (iPS) cells may become a potential source of universal donor Tregs, with optimal immunosuppressive activity after engineering (110). Adoptive therapy of universal donor Tregs may represent a promising approach for patients with GVHD.

\section{TREGS APPLICATION STRATEGIES IN GVHD}

As mentioned above, Tregs play an essential role in maintaining immunological tolerance. Therefore, adoptive transfer of Tregs to directly reduce the incidence or severity of GVHD after alloHSCT has been the focus in the field of transplantation. Main clinical trials have been summarized in Table 1. What is more, increasing the frequency and stability of Tregs in vivo by reagents, such as IL-2, to control excessive immune responses has also aroused interest.

\section{Tregs to Prevent GVHD}

A clinical trial showed that early adoptive transfer of Tregs freshly isolated from donors, followed by conventional $\mathrm{T}$ cells (Tcons) four days later, could prevent GVHD without increasing infection or relapse following haploidentical HSCT, which confirmed the prophylactic efficacy of Tregs against GVHD for the first time (82). Furthermore, Brunstein et al. also confirmed the safety of umbilical Tregs expanded in vitro using IL-2 and $\alpha \mathrm{CD} 3 / \alpha \mathrm{CD} 28$ beads to prevent aGVHD after umbilical cord blood (UCB) transplantation without increasing the likelihood of infection, relapse, or early mortality (83). This study included 23 patients who received UCB-derived Tregs at a dose of $0.1-30 \times$ $10^{5}$ UCB Tregs/kg on day one after transplantation, alongside a cohort receiving a second dose of $30 \times 10^{5} \mathrm{Tregs} / \mathrm{kg}$ at day +15 , and compared with 108 historical controls, the incidence rates of grade II-IV aGVHD were reduced by 43 and $61 \%$, respectively $(\mathrm{P}=0.05)$. A clinical trial of in vivo Treg expansion by injection of ultra-low dose IL-2 also reduced the incidence of GVHD (111); 16 patients were administered with ultra-low doses of IL-2 $(100,000$ units subcutaneously $\times 3$ weekly for $6-12$ weeks $)$ after allo-HSCT. The percentage of Tregs increased after IL-2 therapy, with the mean of $4.8 \%$ rising to $11.1 \%$, and no IL-2 treated patients suffered from grade II-IV aGVHD, compared with $12 \%$ (4/33) of the control group who did not receive IL-2. Besides, Pierini et al. (18) conducted a clinical trial which included 50 patients with acute myeloid leukemia (AML). An age-adapted myeloablative conditioning regimen was combined with Treg/ Tcon adoptive immunotherapy, resulting in an impressive $75 \%$ moderate/severe cGVHD/relapse-free survival rate. Only two of the 50 patients relapsed, and GVL was not impaired by this therapy with Tregs, which may be related to the low levels of CXCR4 bone marrow homing receptor in Tregs.

\section{Tregs to Treat GVHD}

Notably, no large-scale trial of Treg administration to treat GVHD, particularly aGVHD, has been conducted. The first case of cGVHD patients to receive Treg infusion reported an improved outcome,

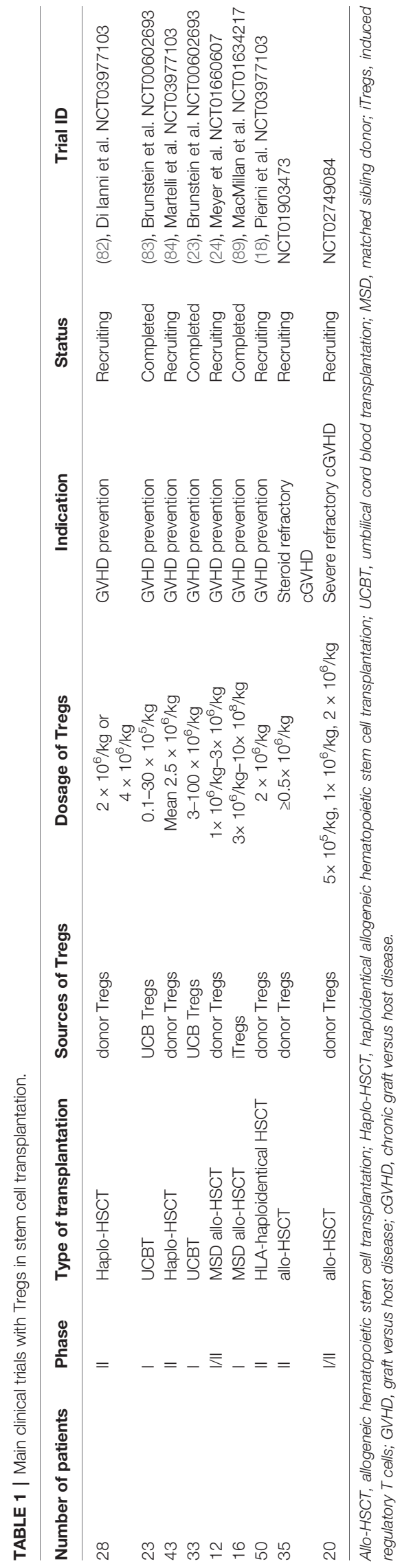


but this was not conclusively demonstrated in patients with aGVHD (15). In another clinical trial, Tregs from HLA-matched donors were administered to five patients with treatment-refractory cGVHD; two patients achieved symptomatic relief, while four had reduced immunosuppressive treatment with increased numbers of Tregs in vivo; however, two patients were diagnosed with skin cancer months after adoptive transfer of Tregs (112). Further studies are needed to evaluate the feasibility of this approach for treating GVHD. Regarding Treg infusion to treat patients with aGVHD, related reports are rare; however, the therapeutic efficacy of Tregs in established aGVHD has been investigated in a mouse model (113). The severity of tissue damage caused by aGVHD was alleviated and Tregs migrated to aGVHD targeted organs and lymphoid sites to exert immunosuppressive function, particularly in the gastrointestinal tract. Mice treated with Tregs showed relief of aGVHD symptoms and achieved prolonged survival (113). These results suggest that adoptive transfer of Tregs to treat aGVHD may be effective, although more studies are required.

\section{Tregs Combined With DLI}

Previous investigations have focused on the feasibility and safety of Tregs' transfer to control GVHD at the time of transplantation. As an effective strategy to rescue patients with relapsed hematological malignancies after allo-HSCT, donor lymphocyte infusion (DLI) can boost GVL to eliminate tumor cells, but increases the risk of severe GVHD (114). Recently, Di Ianni et al. (115) reported the case of a patient with acute promyelocytic leukemia (APL) treated with Treg-protected DLI in the early stage of recurrence after second allo-HSCT. The patient received a first infusion dose of $2.5 \times 10^{6} / \mathrm{kg}$ Tregs, followed by infusion of $5 \times 10^{6} / \mathrm{kg}$ Tcons one week later; a second infusion $\left(2.5 \times 10^{6} / \mathrm{kg}\right.$ Tregs and $2 \times 10^{6} / \mathrm{kg}$ Tcons) was performed two months later. The results demonstrated that complete hematological remission was achieved, with a progression-free survival of 6 months, and no apparent GVHD symptoms were observed. Whether Tregs can be administered with DLI to prevent GVHD deserves more investigation, and this is a potential new strategy to apply Tregs for GVHD control.

\section{Tregs and Immunosuppressive Agents}

Since Tregs play a vital role in maintaining peripheral immune tolerance, pharmacological immunosuppression for GVHD prophylaxis and treatment may influence the regulation of Tregs after allo-HSCT. As hypomethylating agents, azacitidine (AzaC) and decitabine (Dec) can cause $\mathrm{CD} 4^{+} \mathrm{CD} 25^{-} \mathrm{T}$ cells to obtain suppressive properties by inducing FOXP3 expression (116). Thus, the effect of AzaC in mitigating GVHD symptoms without abrogating GVL involves the conversion of alloreactive $\mathrm{T}$ cells to suppress Tregs (116). Further, nTregs are essential for AzaC protection against GVHD, as depletion of nTregs in vivo in mice compromised the effect of AzaC (117). The GVHD prophylactic regimen based on sirolimus without calcineurin inhibitors in patients with high-risk hematological malignancies can promote Treg proliferation and accelerate immune reconstitution in vivo (118). Low-dose post-transplant cyclophosphamide could attenuate and prevent GVHD by increasing Treg frequency, and the effects were enhanced by combination with anti-thymocyte globulin (119). Lee et al. (120) applied metformin and tacrolimus to treat GVHD in mice and found that combined therapy with these two drugs suppressed type 1 helper $\mathrm{T}$ (Th1) and Th17 cell development, while it enhanced the expression of Treg-related genes. This combination therapy alleviated GVHD severity and improved mouse survival. Furthermore, combination treatment also reduced human alloreactive $\mathrm{T}$ cell proliferation and production of proinflammatory cytokines by balancing the Treg/Th17 cells ratio (120). Understanding the effects of pharmaceutical preparations on Tregs could help clinicians to formulate optimal regimens to generate equilibrium between relapse and GVHD, thus achieving immune homeostasis.

\section{DISCUSSION}

Treg administration for GVHD has been investigated for several years. Numerous animal studies have confirmed that Tregs have important roles in restraining excessive immune responses and can prevent GVHD, without increasing the risk of relapse and infection. Tregs may lose their immunosuppressive phenotype due to unstable expression of FOXP3 under inflammatory conditions. Notably, upstream factors that regulate Tregs' stability have not been clearly elucidated; therefore strategies to maintain FOXP3 stability warrant investigation to ensure that Tregs exert a suppressive function after adoptive transfer. The numbers of Tregs available in peripheral blood samples are far from sufficient for clinical application. In addition to exploring methods to effectively freshly isolate high purity Tregs from donors, methods for generating large numbers of functional iTregs in vitro deserve more attention, given the intrinsically unstable properties of Tregs cultured ex vivo. Notably, alloantigen-specific Tregs may possess potent inhibitory function against specific tissues, facilitating achievement of satisfactory suppressive effects using fewer cells. Furthermore, universal Tregs may broaden the utility of Treg infusion, opening a new avenue to resolution of the problem of GVHD after allo-HSCT. Many clinical trials have demonstrated that adoptive transfer of Tregs is an effective and safe way to prevent GVHD, rather than treating GVHD after it occurs. More trials are needed to verify the feasibility of cell therapy based on Treg infusion to treat GVHD, particularly aGVHD.

\section{AUTHOR CONTRIBUTIONS}

W-WG, X-HS and M-YW wrote the manuscript. X-MF, M-ZH and E-LJ revised the manuscript. All authors contributed to the article and approved the submitted version. W-WG and X-HS contributed equally to this manuscript.

\section{FUNDING}

This work was supported by grants from National Natural Science Foundation of China (No. 81670171 and 82070192).

\section{ACKNOWLEDGMENTS}

The pictures were created with BioRender.com 


\section{REFERENCES}

1. Martin PJ, Rizzo JD, Wingard JR, Ballen K, Curtin PT, Cutler C, et al. Firstand Second-Line Systemic Treatment of Acute Graft-Versus-Host Disease: Recommendations of the American Society of Blood and Marrow Transplantation. Biol Blood Marrow Transplant (2012) 18(8):1150-63. doi: 10.1016/j.bbmt.2012.04.005

2. Flowers MED, Martin PJ. How We Treat Chronic Graft-Versus-Host Disease. Blood (2015) 125(4):606-15. doi: 10.1182/blood-2014-08-551994

3. Mielcarek M, Furlong T, Storer BE, Green ML, McDonald GB, Carpenter PA, et al. Effectiveness and Safety of Lower Dose Prednisone for Initial Treatment of Acute Graft-Versus-Host Disease: A Randomized Controlled Trial. Haematologica (2015) 100(6):842-8. doi: 10.3324/haematol.2014.118471

4. Zeiser R, Blazar BR. Acute Graft-Versus-Host Disease - Biologic Process, Prevention, and Therapy. N Engl J Med (2017) 377(22):2167-79. doi: 10.1056/NEJMra1609337

5. Blazar BR, MacDonald KPA, Hill GR. Immune Regulatory Cell Infusion for Graft-Versus-Host Disease Prevention and Therapy. Blood (2018) 131 (24):2651-60. doi: 10.1182/blood-2017-11-785865

6. Sakaguchi S, Sakaguchi N, Asano M, Itoh M, Toda M. Immunologic SelfTolerance Maintained by Activated T Cells Expressing IL-2 Receptor AlphaChains (CD25). Breakdown of a Single Mechanism of Self-Tolerance Causes Various Autoimmune Diseases. J Immunol (1995) 155(3):1151-64.

7. Fontenot JD, Gavin MA, Rudensky AY. Foxp3 Programs the Development and Function of CD4+CD25+ Regulatory T Cells. Nat Immunol (2003) 4 (4):330-6. doi: 10.1038/ni904

8. Liu W, Putnam AL, Xu-Yu Z, Szot GL, Lee MR, Zhu S, et al. CD127 Expression Inversely Correlates With FoxP3 and Suppressive Function of Human CD4+ T Reg Cells. J Exp Med (2006) 203(7):1701-11. doi: 10.1084/ jem.20060772

9. Taylor PA, Noelle RJ, Blazar BR. CD4(+)CD25(+) Immune Regulatory Cells are Required for Induction of Tolerance to Alloantigen Via Costimulatory Blockade. J Exp Med (2001) 193(11):1311-8. doi: 10.1084/jem.193.11.1311

10. Hara M, Kingsley CI, Niimi M, Read S, Turvey SE, Bushell AR, et al. IL-10 Is Required for Regulatory T Cells to Mediate Tolerance to Alloantigens In Vivo. J Immunol (2001) 166(6):3789-96. doi: 10.4049/jimmunol.166.6.3789

11. Gregori S, Casorati M, Amuchastegui S, Smiroldo S, Davalli AM, Adorini L. Regulatory $\mathrm{T}$ Cells Induced by 1 Alpha,25-Dihydroxyvitamin D3 and Mycophenolate Mofetil Treatment Mediate Transplantation Tolerance. J Immunol (2001) 167(4):1945-53. doi: 10.4049/jimmunol.167.4.1945

12. Cohen JL, Trenado A, Vasey D, Klatzmann D, Salomon BL. CD4(+)CD25 (+) Immunoregulatory T Cells: New Therapeutics for Graft-Versus-Host Disease. J Exp Med (2002) 196(3):401-6. doi: 10.1084/jem.20020090

13. Nguyen VH, Zeiser R, Dasilva DL, Chang DS, Beilhack A, Contag CH, et al. In Vivo Dynamics of Regulatory $\mathrm{T}$-cell Trafficking and Survival Predict Effective Strategies to Control Graft-Versus-Host Disease Following Allogeneic Transplantation. Blood (2007) 109(6):2649-56. doi: 10.1182/ blood-2006-08-044529

14. Nguyen VH, Shashidhar S, Chang DS, Ho L, Kambham N, Bachmann M, et al. The Impact of Regulatory T Cells on T-Cell Immunity Following Hematopoietic Cell Transplantation. Blood (2008) 111(2):945-53. doi: 10.1182/blood-2007-07-103895

15. Trzonkowski P, Bieniaszewska M, Juścińska J, Dobyszuk A, Krzystyniak A, Marek N, et al. First-in-Man Clinical Results of the Treatment of Patients With Graft Versus Host Disease With Human Ex Vivo Expanded CD4 +CD25+CD127- T Regulatory Cells. Clin Immunol (2009) 133(1):22-6. doi: 10.1016/j.clim.2009.06.001

16. Copsel S, Wolf D, Kale B, Barreras H, Lightbourn CO, Bader CS, et al. Very Low Numbers of CD4(+) FoxP3(+) Tregs Expanded in Donors Via TL1A-Ig and Low-Dose Il-2 Exhibit a Distinct Activation/Functional Profile and Suppress GVHD in a Preclinical Model. Biol Blood Marrow Transplant (2018) 24(9):1788-94. doi: 10.1016/j.bbmt.2018.04.026

17. Wolf D, Barreras H, Bader CS, Copsel S, Lightbourn CO, Pfeiffer BJ, et al. Marked in Vivo Donor Regulatory T Cell Expansion Via Interleukin-2 and TL1A-Ig Stimulation Ameliorates Graft-Versus-Host Disease But Preserves Graft-versus-Leukemia in Recipients After Hematopoietic Stem Cell Transplantation. Biol Blood Marrow Transplant (2017) 23(5):757-66. doi: 10.1016/j.bbmt.2017.02.013
18. Pierini A, Ruggeri L, Carotti A, Falzetti F, Saldi S, Terenzi A, et al. Haploidentical Age-Adapted Myeloablative Transplant and Regulatory and Effector T Cells for Acute Myeloid Leukemia. Blood Adv (2021) 5 (5):1199-208. doi: 10.1182/bloodadvances.2020003739

19. Zheng J, Liu Y, Liu Y, Liu M, Xiang Z, Lam K-T, et al. Human CD8+ Regulatory T Cells Inhibit GVHD and Preserve General Immunity in Humanized Mice. Sci Trans Med (2013) 5(168):168ra9. doi: 10.1126/ scitranslmed. 3004943

20. Bézie S, Anegon I, Guillonneau C. Advances on CD8+ Treg Cells and Their Potential in Transplantation. Transplantation (2018) 102(9):1467-78. doi: 10.1097/TP.0000000000002258

21. Peters C, Oberg H-H, Kabelitz D, Wesch D. Phenotype and Regulation of Immunosuppressive V $\delta 2$-Expressing $\gamma \delta$ T Cells. Cell Mol Life Sci (2014) 71 (10):1943-60. doi: 10.1007/s00018-013-1467-1

22. Xuan L, Wu X, Qiu D, Gao L, Liu H, Fan Z, et al. Regulatory $\gamma \delta$ T Cells Induced by G-CSF Participate in Acute Graft-Versus-Host Disease Regulation in G-CSFmobilized Allogeneic Peripheral Blood Stem Cell Transplantation. J Trans Med (2018) 16(1):144. doi: 10.1186/s12967-018-1519-2

23. Brunstein CG, Miller JS, McKenna DH, Hippen KL, DeFor TE, Sumstad D, et al. Umbilical Cord Blood-Derived T Regulatory Cells to Prevent GVHD: Kinetics, Toxicity Profile, and Clinical Effect. Blood (2016) 127(8):1044-51. doi: 10.1182/blood-2015-06-653667

24. Meyer EH, Laport G, Xie BJ, MacDonald K, Heydari K, Sahaf B, et al. Transplantation of Donor Grafts With Defined Ratio of Conventional and Regulatory T Cells in HLA-Matched Recipients. JCI Insight (2019) 4(10): e127244. doi: $10.1172 /$ jci.insight.127244

25. Dominguez-Villar M, Hafler DA. Regulatory T Cells in Autoimmune Disease. Nat Immunol (2018) 19(7):665-73. doi: 10.1038/s41590-018-0120-4

26. Josefowicz SZ, Lu L-F, Rudensky AY. Regulatory T Cells: Mechanisms of Differentiation and Function. Annu Rev Immunol (2012) 30:531-64. doi: 10.1146/annurev.immunol.25.022106.141623

27. Jordan MS, Boesteanu A, Reed AJ, Petrone AL, Holenbeck AE, Lerman MA, et al. Thymic Selection of CD4+CD25+ Regulatory T Cells Induced by an Agonist Self-Peptide. Nat Immunol (2001) 2(4):301-6. doi: 10.1038/86302

28. Chen W, Jin W, Hardegen N, Lei K-J, Li L, Marinos N, et al. Conversion of Peripheral CD4+CD25- Naive T Cells to CD4+CD25+ Regulatory T Cells by TGF-Beta Induction of Transcription Factor Foxp3. J Exp Med (2003) 198 (12):1875-86. doi: 10.1084/jem.20030152

29. Kanamori $\mathrm{M}$, Nakatsukasa $\mathrm{H}$, Okada $\mathrm{M}, \mathrm{Lu} \mathrm{Q}$, Yoshimura A. Induced Regulatory T Cells: Their Development, Stability, and Applications. Trends Immunol (2016) 37(11):803-11. doi: 10.1016/j.it.2016.08.012

30. Haribhai D, Williams JB, Jia S, Nickerson D, Schmitt EG, Edwards B, et al. A Requisite Role for Induced Regulatory T Cells in Tolerance Based on Expanding Antigen Receptor Diversity. Immunity (2011) 35(1):109-22. doi: 10.1016/j.immuni.2011.03.029

31. Thorstenson KM, Khoruts A. Generation of Anergic and Potentially Immunoregulatory CD25+CD4 $\mathrm{T}$ Cells In Vivo After Induction of Peripheral Tolerance With Intravenous or Oral Antigen. I Immunol (2001) 167(1):188-95. doi: 10.4049/jimmunol.167.1.188

32. Lathrop SK, Bloom SM, Rao SM, Nutsch K, Lio CW, Santacruz N, et al. Peripheral Education of the Immune System by Colonic Commensal Microbiota. Nature (2011) 478(7368):250-4. doi: 10.1038/nature10434

33. Yadav M, Louvet C, Davini D, Gardner JM, Martinez-Llordella M, BaileyBucktrout S, et al. Neuropilin-1 Distinguishes Natural and Inducible Regulatory T Cells Among Regulatory T Cell Subsets In Vivo. J Exp Med (2012) 209(10):1713-22, s1-19. doi: 10.1084/jem.20120822

34. Floess S, Freyer J, Siewert C, Baron U, Olek S, Polansky J, et al. Epigenetic Control of the Foxp3 Locus in Regulatory T Cells. PloS Biol (2007) 5(2):e38. doi: 10.1371/journal.pbio.0050038

35. Huehn J, Beyer M. Epigenetic and Transcriptional Control of Foxp3+ Regulatory T Cells. Semin Immunol (2015) 27(1):10-8. doi: 10.1016/ j.smim.2015.02.002

36. Zhou X, Bailey-Bucktrout SL, Jeker LT, Penaranda C, Martínez-Llordella M, Ashby M, et al. Instability of the Transcription Factor Foxp3 Leads to the Generation of Pathogenic Memory T Cells In Vivo. Nat Immunol (2009) 10 (9):1000-7. doi: 10.1038/ni.1774

37. Wu D, Luo Y, Guo W, Niu Q, Xue T, Yang F, et al. Lkb1 Maintains T(reg) Cell Lineage Identity. Nat Commun (2017) 8:15876. doi: 10.1038/ncomms15876 
38. Yang K, Blanco DB, Neale G, Vogel P, Avila J, Clish CB, et al. Homeostatic Control of Metabolic and Functional Fitness of T(reg) Cells by LKB1 Signalling. Nature (2017) 548(7669):602-6. doi: 10.1038/nature23665

39. He N, Fan W, Henriquez B, Yu RT, Atkins AR, Liddle C, et al. Metabolic Control of Regulatory T Cell (Treg) Survival and Function by Lkb1. Proc Natl Acad Sci U S A (2017) 114(47):12542-7. doi: 10.1073/pnas.1715363114

40. Su X, Wang Q, Guo W, Pei X, Niu Q, Liu M, et al. Loss of Lkb1 Impairs Treg Function and Stability to Aggravate Graft-Versus-Host Disease After Bone Marrow Transplantation. Cell Mol Immunol (2020) 17(5):483-95. doi: 10.1038/s41423-019-0312-3

41. Lewis BP, Burge CB, Bartel DP. Conserved Seed Pairing, Often Flanked by Adenosines, Indicates That Thousands of Human Genes Are microRNA Targets. Cell (2005) 120(1):15-20. doi: 10.1016/j.cell.2004.12.035

42. Cobb BS, Hertweck A, Smith J, O'Connor E, Graf D, Cook T, et al. A Role for Dicer in Immune Regulation. J Exp Med (2006) 203(11):2519-27. doi: 10.1084/jem.20061692

43. Lu Y, Hippen KL, Lemire AL, Gu J, Wang W, Ni X, et al. miR-146b Antagomir-Treated Human Tregs Acquire Increased GVHD Inhibitory Potency. Blood (2016) 128(10):1424-35. doi: 10.1182/blood-2016-05714535

44. Zhang Y, Liu W, Chen Y, Liu J, Wu K, Su L, et al. A Cellular Microrna Facilitates Regulatory T Lymphocyte Development by Targeting the Promoter TATA-Box Motif. J Immunol (2018) 200(3):1053-63. doi: 10.4049/jimmunol.1700196

45. Gao J, Gu J, Pan X, Gan X, Ju Z, Zhang S, et al. Blockade of miR-142-3p Promotes Anti-Apoptotic and Suppressive Function by Inducing KDM6Amediated H3k27me3 Demethylation in Induced Regulatory T Cells. Cell Death Dis (2019) 10(5):332. doi: 10.1038/s41419-019-1565-6

46. Magenau J, Runaas L, Reddy P. Advances in Understanding the Pathogenesis of Graft-Versus-Host Disease. Br J Haematol (2016) 173 (2):190-205. doi: 10.1111/bjh.13959

47. Ferrara JLM, Levine JE, Reddy P, Holler E. Graft-Versus-Host Disease. Lancet (2009) 373(9674):1550-61. doi: 10.1016/S0140-6736(09)60237-3

48. Heinrichs J, Bastian D, Veerapathran A, Anasetti C, Betts B, Yu X-Z. Regulatory T-Cell Therapy for Graft-Versus-Host Disease. J Immunol Res Ther (2016) 1(1):1-14.

49. Beres AJ, Drobyski WR. The Role of Regulatory T Cells in the Biology of Graft Versus Host Disease. Front Immunol (2013) 4:163. doi: 10.3389/ fimmu.2013.00163

50. Chen X, Das R, Komorowski R, Beres A, Hessner MJ, Mihara M, et al. Blockade of Interleukin-6 Signaling Augments Regulatory T-Cell Reconstitution and Attenuates the Severity of Graft-Versus-Host Disease. Blood (2009) 114(4):891-900. doi: 10.1182/blood-2009-01-197178

51. Chen X, Vodanovic-Jankovic S, Johnson B, Keller M, Komorowski R, Drobyski WR. Absence of Regulatory T-Cell Control of TH1 and TH17 Cells is Responsible for the Autoimmune-Mediated Pathology in Chronic Graft-Versus-Host Disease. Blood (2007) 110(10):3804-13. doi: 10.1182/ blood-2007-05-091074

52. Miura Y, Thoburn CJ, Bright EC, Phelps ML, Shin T, Matsui EC, et al. Association of Foxp3 Regulatory Gene Expression With Graft-Versus-Host Disease. Blood (2004) 104(7):2187-93. doi: 10.1182/blood-2004-03-1040

53. Taylor PA, Lees CJ, Blazar BR. The Infusion of Ex Vivo Activated and Expanded CD4(+)CD25(+) Immune Regulatory Cells Inhibits GraftVersus-Host Disease Lethality. Blood (2002) 99(10):3493-9. doi: 10.1182/ blood.V99.10.3493

54. Bolton HA, Zhu E, Terry AM, Guy TV, Koh W-P, Tan S-Y, et al. Selective Treg Reconstitution During Lymphopenia Normalizes DC Costimulation and Prevents Graft-Versus-Host Disease. J Clin Invest (2015) 125(9):362741. doi: $10.1172 /$ JCI76031

55. Vignali DAA, Collison LW, Workman CJ. How Regulatory T Cells Work. Nat Rev Immunol (2008) 8(7):523-32. doi: 10.1038/nri2343

56. Collison LW, Workman CJ, Kuo TT, Boyd K, Wang Y, Vignali KM, et al. The Inhibitory Cytokine IL-35 Contributes to Regulatory T-Cell Function. Nature (2007) 450(7169):566-9. doi: 10.1038/nature06306

57. Nakamura K, Kitani A, Strober W. Cell Contact-Dependent Immunosuppression by CD4(+)CD25(+) Regulatory T Cells is Mediated by Cell Surface-Bound Transforming Growth Factor Beta. J Exp Med (2001) 194 (5):629-44. doi: 10.1084/jem.194.5.629
58. Tang Q, Adams JY, Tooley AJ, Bi M, Fife BT, Serra P, et al. Visualizing Regulatory T Cell Control of Autoimmune Responses in Nonobese Diabetic Mice. Nat Immunol (2006) 7(1):83-92. doi: 10.1038/ni1289

59. Mancusi A, Piccinelli S, Velardi A, Pierini A. CD4(+)FOXP3(+) Regulatory T Cell Therapies in HLA Haploidentical Hematopoietic Transplantation. Front Immunol (2019) 10:2901. doi: 10.3389/fimmu.2019.02901

60. Yu H, Tian Y, Wang Y, Mineishi S, Zhang Y. Dendritic Cell Regulation of Graft-Vs.-Host Disease: Immunostimulation and Tolerance. Front Immunol (2019) 10:93. doi: 10.3389/fimmu.2019.00093

61. Matte CC, Liu J, Cormier J, Anderson BE, Athanasiadis I, Jain D, et al. Donor APCs Are Required for Maximal GVHD But Not for GVL. Nat Med (2004) 10(9):987-92. doi: 10.1038/nm1089

62. Koyama M, Hashimoto D, Aoyama K, Matsuoka K-I, Karube K, Niiro H, et al. Plasmacytoid Dendritic Cells Prime Alloreactive T Cells to Mediate Graft-Versus-Host Disease as Antigen-Presenting Cells. Blood (2009) 113 (9):2088-95. doi: 10.1182/blood-2008-07-168609

63. Shlomchik WD. Graft-Versus-Host Disease. Nat Rev Immunol (2007) 7 (5):340-52. doi: 10.1038/nri2000

64. Teshima T, Reddy P, Lowler KP, KuKuruga MA, Liu C, Cooke KR, et al. Flt3 Ligand Therapy for Recipients of Allogeneic Bone Marrow Transplants Expands Host CD8 Alpha(+) Dendritic Cells and Reduces Experimental Acute Graft-Versus-Host Disease. Blood (2002) 99(5):1825-32. doi: 10.1182/ blood.V99.5.1825

65. Weber M, Rudolph B, Stein P, Yogev N, Bosmann M, Schild H, et al. HostDerived $\mathrm{CD}^{+}$Dendritic Cells Protect Against Acute Graft-Versus-Host Disease After Experimental Allogeneic Bone Marrow Transplantation. Biol Blood Marrow Transplant (2014) 20(11):1696-704. doi: 10.1016/ j.bbmt.2014.08.005

66. Collins AV, Brodie DW, Gilbert RJC, Iaboni A, Manso-Sancho R, Walse B, et al. The Interaction Properties of Costimulatory Molecules Revisited. Immunity (2002) 17(2):201-10. doi: 10.1016/S1074-7613(02)00362-X

67. Qureshi OS, Zheng Y, Nakamura K, Attridge K, Manzotti C, Schmidt EM, et al. Trans-Endocytosis of CD80 and CD86: A Molecular Basis for the CellExtrinsic Function of CTLA-4. Science (2011) 332(6029):600-3. doi: 10.1126/science.1202947

68. Mittal SK, Roche PA. Suppression of Antigen Presentation by IL-10. Curr Opin Immunol (2015) 34:22-7. doi: 10.1016/j.coi.2014.12.009

69. Bayry J, Triebel F, Kaveri SV, Tough DF. Human Dendritic Cells Acquire a Semimature Phenotype and Lymph Node Homing Potential Through Interaction With CD4+CD25+ Regulatory T Cells. J Immunol (2007) 178 (7):4184-93. doi: 10.4049/jimmunol.178.7.4184

70. Mavin E, Nicholson L, Rafez Ahmed S, Gao F, Dickinson A, Wang X-N. Human Regulatory T Cells Mediate Transcriptional Modulation of Dendritic Cell Function. J Immunol (2017) 198(1):138-46. doi: 10.4049/ jimmunol.1502487

71. Misra N, Bayry J, Lacroix-Desmazes S, Kazatchkine MD, Kaveri SV. Cutting Edge: Human CD4+CD25+ T Cells Restrain the Maturation and AntigenPresenting Function of Dendritic Cells. J Immunol (2004) 172(8):4676-80. doi: 10.4049/jimmunol.172.8.4676

72. Liang B, Workman C, Lee J, Chew C, Dale BM, Colonna L, et al. Regulatory T Cells Inhibit Dendritic Cells by Lymphocyte Activation Gene-3 Engagement of MHC Class II. J Immunol (2008) 180(9):5916-26. doi: 10.4049/jimmunol.180.9.5916

73. Lu Y, Giver CR, Sharma A, Li JM, Darlak KA, Owens LM, et al. IFN- $\gamma$ and Indoleamine 2,3-Dioxygenase Signaling Between Donor Dendritic Cells and T Cells Regulates Graft Versus Host and Graft Versus Leukemia Activity. Blood (2012) 119(4):1075-85. doi: 10.1182/blood-2010-12322891

74. Chen J, Zhou Y, Chen S, Liu M, Guo W, Wang Q, et al. Lkb1 in Dendritic Cells Restricts CD8(+)Foxp3(+)Regulatory T Cells Expansion In Vivo. Exp Cell Res (2019) 384(2):111650. doi: 10.1016/j.yexcr.2019.111650

75. Wang Y, Du X, Wei J, Long L, Tan H, Guy C, et al. LKB1 Orchestrates Dendritic Cell Metabolic Quiescence and Anti-Tumor Immunity. Cell Res (2019) 29(5):391-405. doi: 10.1038/s41422-019-0157-4

76. Pelgrom LR, Patente TA, Sergushichev A, Esaulova E, Otto F, OzirFazalalikhan A, et al. LKB1 Expressed in Dendritic Cells Governs the Development and Expansion of Thymus-Derived Regulatory T Cells. Cell Res (2019) 29(5):406-19. doi: 10.1038/s41422-019-0161-8 
77. Hotta M, Yoshimura H, Satake A, Tsubokura Y, Ito T, Nomura S. GM-CSF Therapy Inhibits Chronic Graft-Versus-Host Disease Via Expansion of Regulatory T Cells. Eur J Immunol (2019) 49(1):179-91. doi: 10.1002/ eji.201847684

78. Edinger M, Hoffmann P, Ermann J, Drago K, Fathman CG, Strober S, et al. CD4+CD25+ Regulatory T Cells Preserve Graft-Versus-Tumor Activity While Inhibiting Graft-Versus-Host Disease After Bone Marrow Transplantation. Nat Med (2003) 9(9):1144-50. doi: 10.1038/nm915

79. Trenado A, Charlotte F, Fisson S, Yagello M, Klatzmann D, Salomon BL, et al. Recipient-Type Specific CD4+CD25+ Regulatory T Cells Favor Immune Reconstitution and Control Graft-Versus-Host Disease While Maintaining Graft-Versus-Leukemia. J Clin Invest (2003) 112(11):1688-96. doi: 10.1172/JCI17702

80. Zhang P, Tey S-K, Koyama M, Kuns RD, Olver SD, Lineburg KE, et al. Induced Regulatory $\mathrm{T}$ Cells Promote Tolerance When Stabilized by Rapamycin and IL-2 In Vivo. J Immunol (2013) 191(10):5291-303. doi: 10.4049/jimmunol.1301181

81. Heinrichs J, Li J, Nguyen H, Wu Y, Bastian D, Daethanasanmak A, et al. CD8 (+) Tregs Promote GVHD Prevention and Overcome the Impaired GVL Effect Mediated by CD4(+) Tregs in Mice. Oncoimmunology (2016) 5(6): e1146842. doi: 10.1080/2162402X.2016.1146842

82. Di Ianni M, Falzetti F, Carotti A, Terenzi A, Castellino F, Bonifacio E, et al. Tregs Prevent GVHD and Promote Immune Reconstitution in HLA-haploidentical Transplantation. Blood (2011) 117(14):3921-8. doi: 10.1182/blood-2010-10311894

83. Brunstein CG, Miller JS, Cao Q, McKenna DH, Hippen KL, Curtsinger J, et al. Infusion of Ex Vivo Expanded T Regulatory Cells in Adults Transplanted With Umbilical Cord Blood: Safety Profile and Detection Kinetics. Blood (2011) 117(3):1061-70. doi: 10.1182/blood-2010-07-293795

84. Martelli MF, Di Ianni M, Ruggeri L, Falzetti F, Carotti A, Terenzi A, et al. HLA-Haploidentical Transplantation With Regulatory and Conventional TCell Adoptive Immunotherapy Prevents Acute Leukemia Relapse. Blood (2014) 124(4):638-44. doi: 10.1182/blood-2014-03-564401

85. Marín Morales JM, Münch N, Peter K, Freund D, Oelschlägel U, Hölig K, et al. Automated Clinical Grade Expansion of Regulatory T Cells in a Fully Closed System. Front Immunol (2019) 10:38. doi: 10.3389/fimmu.2019.00038

86. Del Papa B, Ruggeri L, Urbani E, Baldoni S, Cecchini D, Zei T, et al. ClinicalGrade-Expanded Regulatory T Cells Prevent Graft-Versus-Host Disease While Allowing a Powerful T Cell-Dependent Graft-Versus-Leukemia Effect in Murine Models. Biol Blood Marrow Transplant (2017) 23 (11):1847-51. doi: 10.1016/j.bbmt.2017.07.009

87. Ulbar F, Villanova I, Giancola R, Baldoni S, Guardalupi F, Fabi B, et al. Clinical-Grade Expanded Regulatory T Cells Are Enriched With Highly Suppressive Cells Producing IL-10, Granzyme B, and IL-35. Biol Blood Marrow Transplant (2020) 26(12):2204-10. doi: 10.1016/j.bbmt.2020.08.034

88. Kasahara H, Kondo T, Nakatsukasa H, Chikuma S, Ito M, Ando M, et al. Generation of Allo-Antigen-Specific Induced Treg Stabilized by Vitamin C Treatment and its Application for Prevention of Acute Graft Versus Host Disease Model. Int Immunol (2017) 29(10):457-69. doi: 10.1093/intimm/ dxx060

89. MacMillan ML, Hippen KL, McKenna DH, Kadidlo D, Sumstad D, DeFor TE, et al. First-in-Human Phase 1 Trial of Induced Regulatory T Cells for Graft-Versus-Host Disease Prophylaxis in HLA-Matched Siblings. Blood Adv (2021) 5(5):1425-36. doi: 10.1182/bloodadvances.2020003219

90. Koenecke C, Czeloth N, Bubke A, Schmitz S, Kissenpfennig A, Malissen B, et al. Alloantigen-Specific De Novo-Induced Foxp3+ Treg Revert In Vivo and do Not Protect From Experimental GVHD. Eur J Immunol (2009) 39 (11):3091-6. doi: 10.1002/eji.200939432

91. Betts BC, Veerapathran A, Pidala J, Yu X-Z, Anasetti C. STAT5 Polarization Promotes iTregs and Suppresses Human T-Cell Alloresponses While Preserving CTL Capacity. J Leukoc Biol (2014) 95(2):205-13. doi: 10.1189/ jlb.0313154

92. Walton K, Fernandez MR, Sagatys EM, Reff J, Kim J, Lee MC, et al. Metabolic Reprogramming Augments Potency of Human pSTAT3Inhibited iTregs to Suppress Alloreactivity. JCI Insight (2020) 5(9): e136437. doi: 10.1172/jci.insight.136437

93. Rosenkranz E, Metz CHD, Maywald M, Hilgers R-D, Weßels I, Senff T, et al. Zinc Supplementation Induces Regulatory T Cells by Inhibition of Sirt-1
Deacetylase in Mixed Lymphocyte Cultures. Mol Nutr Food Res (2016) 60 (3):661-71. doi: 10.1002/mnfr.201500524

94. Fujioka T, Tamaki H, Ikegame K, Yoshihara S, Taniguchi K, Kaida K, et al. Frequency of CD4(+)FOXP3(+) Regulatory T-Cells at Early Stages After HLA-mismatched Allogeneic Hematopoietic SCT Predicts the Incidence of Acute GVHD. Bone Marrow Transplant (2013) 48(6):859-64. doi: 10.1038/ bmt.2012.232

95. Nelson BH. IL-2, Regulatory T Cells, and Tolerance. J Immunol (2004) 172 (7):3983-8. doi: 10.4049/jimmunol.172.7.3983

96. Koreth J, Matsuoka K-I, Kim HT, McDonough SM, Bindra B, Alyea EP, et al. Interleukin-2 and Regulatory $\mathrm{T}$ Cells in Graft-Versus-Host Disease. N Engl J Med (2011) 365(22):2055-66. doi: 10.1056/NEJM oa1108188

97. Hirakawa M, Matos TR, Liu H, Koreth J, Kim HT, Paul NE, et al. Low-Dose IL-2 Selectively Activates Subsets of CD4 Tregs and NK Cells. JCI Insight (2016) 1(18):e89278. doi: 10.1172/jci.insight.89278

98. Trotta E, Bessette PH, Silveria SL, Ely LK, Jude KM, Le DT, et al. A Human Anti-IL-2 Antibody That Potentiates Regulatory T Cells by a StructureBased Mechanism. Nat Med (2018) 24(7):1005-14. doi: 10.1038/s41591018-0070-2

99. Hirai T, Ramos TL, Lin P-Y, Simonetta F, Su LL, Picton LK, et al. Selective Expansion of Regulatory T Cells Using an Orthogonal IL-2/IL-2 Receptor System Facilitates Transplantation Tolerance. J Clin Invest (2021) 131(8): e139991. doi: 10.1172/JCI139991

100. Duramad O, Laysang A, Li J, Ishii Y, Namikawa R. Pharmacologic Expansion of Donor-Derived, Naturally Occurring CD4(+)Foxp3(+) Regulatory T Cells Reduces Acute Graft-Versus-Host Disease Lethality Without Abrogating the Graft-Versus-Leukemia Effect in Murine Models. Biol Blood Marrow Transplant (2011) 17(8):1154-68. doi: 10.1016/j.bbmt.2010.11.022

101. Chen Y-B, Efebera YA, Johnston L, Ball ED, Avigan D, Lekakis LJ, et al. Increased Foxp3Helios Regulatory $\mathrm{T}$ Cells and Decreased Acute GraftVersus-Host Disease After Allogeneic Bone Marrow Transplantation in Patients Receiving Sirolimus and RGI-2001, an Activator of Invariant Natural Killer T Cells. Biol Blood Marrow Transplant (2017) 23(4):625-34 doi: 10.1016/j.bbmt.2017.01.069

102. Kim B-S, Nishikii H, Baker J, Pierini A, Schneidawind D, Pan Y, et al. Treatment With Agonistic DR3 Antibody Results in Expansion of Donor Tregs and Reduced Graft-Versus-Host Disease. Blood (2015) 126(4):546-57. doi: 10.1182/blood-2015-04-637587

103. Nishikii H, Kim B-S, Yokoyama Y, Chen Y, Baker J, Pierini A, et al. DR3 Signaling Modulates the Function of Foxp3+ Regulatory T Cells and the Severity of Acute Graft-Versus-Host Disease. Blood (2016) 128(24):2846-58 doi: 10.1182/blood-2016-06-723783

104. Mavers M, Simonetta F, Nishikii H, Ribado JV, Maas-Bauer K, Alvarez M, et al. Activation of the DR3-TL1A Axis in Donor Mice Leads to Regulatory T Cell Expansion and Activation With Reduction in GraftVersus-Host Disease. Front Immunol (2019) 10:1624. doi: 10.3389/ fimmu.2019.01624

105. Lim J-Y, Im K-I, Song Y, Kim N, Nam Y-S, Jeon Y-W, et al. Third-Party Regulatory T Cells Prevent Murine Acute Graft-Versus-Host Disease. Korean J Internal Med (2018) 33(5):980-9. doi: 10.3904/kjim.2016.319

106. Parmar S, Liu X, Tung SS, Robinson SN, Rodriguez G, Cooper LJ, et al. Third-Party Umbilical Cord Blood-Derived Regulatory T Cells Prevent Xenogenic Graft-Versus-Host Disease. Cytotherapy (2014) 16(1):90-100. doi: 10.1016/j.jcyt.2013.07.009

107. Dijke IE, Hoeppli RE, Ellis T, Pearcey J, Huang Q, McMurchy AN, et al. Discarded Human Thymus Is a Novel Source of Stable and Long-Lived Therapeutic Regulatory T Cells. Am J Transplant (2016) 16(1):58-71. doi: 10.1111/ajt.13456

108. MacDonald KG, Hoeppli RE, Huang Q, Gillies J, Luciani DS, Orban PC, et al. Alloantigen-Specific Regulatory T Cells Generated With a Chimeric Antigen Receptor. J Clin Invest (2016) 126(4):1413-24. doi: 10.1172/ JCI82771

109. Martin A, Daris M, Johnston JA, Cui J. HLA-A*02:01-directed Chimeric Antigen Receptor/Forkhead Box P3-engineered CD4+ T Cells Adopt a Regulatory Phenotype and Suppress Established Graft-Versus-Host Disease. Cytotherapy (2021) 23(2):131-6. doi: 10.1016/j.jcyt.2020.10.002 
110. Raffin C, Vo LT, Bluestone JA. T(Reg) Cell-Based Therapies: Challenges and Perspectives. Nat Rev Immunol (2020) 20(3):158-72. doi: 10.1038/s41577019-0232-6

111. Kennedy-Nasser AA, Ku S, Castillo-Caro P, Hazrat Y, Wu M-F, Liu H, et al. Ultra Low-Dose IL-2 for GVHD Prophylaxis After Allogeneic Hematopoietic Stem Cell Transplantation Mediates Expansion of Regulatory T Cells Without Diminishing Antiviral and Antileukemic Activity. Clin Cancer Res (2014) 20(8):2215-25. doi: 10.1158/10780432.CCR-13-3205

112. Theil A, Tuve S, Oelschlägel U, Maiwald A, Döhler D, Oßmann D, et al. Adoptive Transfer of Allogeneic Regulatory T Cells Into Patients With Chronic Graft-Versus-Host Disease. Cytotherapy (2015) 17(4):473-86. doi: 10.1016/j.jcyt.2014.11.005

113. Riegel C, Boeld TJ, Doser K, Huber E, Hoffmann P, Edinger M. Efficient Treatment of Murine Acute GvHD by In Vitro Expanded Donor Regulatory T Cells. Leukemia (2020) 34(3):895-908. doi: 10.1038/s41375-019-0625-3

114. Wang Y, Chen $\mathrm{H}$, Chen J, Han M, Hu J, Jiong H, et al. The Consensus on the Monitoring, Treatment, and Prevention of Leukemia Relapse After Allogeneic Hematopoietic Stem Cell Transplantation in China. Cancer Lett (2018) 438:63-75. doi: 10.1016/j.canlet.2018.08.030

115. Di Ianni M, Olioso P, Giancola R, Santarone S, Natale A, Papalinetti G, et al. Treg-Protected Donor Lymphocyte Infusions: A New Tool to Address the Graft-Versus-Leukemia Effect in the Absence of Graft-Versus-Host Disease in Patients Relapsed After HSCT. Int J Hematol (2017) 106(6):860-4. doi: 10.1007/s12185-017-2292-3

116. Choi J, Ritchey J, Prior JL, Holt M, Shannon WD, Deych E, et al. In Vivo Administration of Hypomethylating Agents Mitigate Graft-Versus-Host Disease Without Sacrificing Graft-Versus-Leukemia. Blood (2010) 116 (1):129-39. doi: 10.1182/blood-2009-12-257253
117. Cooper ML, Choi J, Karpova D, Vij K, Ritchey J, Schroeder MA, et al. Azacitidine Mitigates Graft-Versus-Host Disease Via Differential Effects on the Proliferation of T Effectors and Natural Regulatory T Cells In Vivo. J Immunol (2017) 198(9):3746-54. doi: 10.4049/jimmunol.1502399

118. Peccatori J, Forcina A, Clerici D, Crocchiolo R, Vago L, Stanghellini MTL et al. Sirolimus-Based Graft-Versus-Host Disease Prophylaxis Promotes the In Vivo Expansion of Regulatory T Cells and Permits Peripheral Blood Stem Cell Transplantation From Haploidentical Donors. Leukemia (2015) 29 (2):396-405. doi: 10.1038/leu.2014.180

119. Wang Y, Chang Y-J, Chen L, Xu L-P, Bian Z-L, Zhang X-H, et al. Low-Dose Post-Transplant Cyclophosphamide Can Mitigate GVHD and Enhance the G-CSF/ATG Induced GVHD Protective Activity and Improve Haploidentical Transplant Outcomes. Oncoimmunology (2017) 6(11): e1356152. doi: 10.1080/2162402X.2017.1356152

120. Lee SK, Park M-J, Jhun JY, Beak J-A, Choi JW, Rye J-Y, et al. Combination Treatment With Metformin and Tacrolimus Improves Systemic Immune Cellular Homeostasis by Modulating Treg and Th17 Imbalance. Front Immunol (2020) 11:581728. doi: 10.3389/fimmu.2020.581728

Conflict of Interest: The authors declare that the research was conducted in the absence of any commercial or financial relationships that could be construed as a potential conflict of interest.

Copyright (c) 2021 Guo, Su, Wang, Han, Feng and Jiang. This is an open-access article distributed under the terms of the Creative Commons Attribution License (CC BY). The use, distribution or reproduction in other forums is permitted, provided the original author(s) and the copyright owner(s) are credited and that the original publication in this journal is cited, in accordance with accepted academic practice. No use, distribution or reproduction is permitted which does not comply with these terms. 